\title{
Imigrantes de Leste na Área Metropolitana de Lisboa Novos Fluxos, Novos Perfis?
}

Pedro Perista*

\begin{abstract}
$\mathrm{R}$ Resumo: O arligo apresenta, de forma breve, alguns dos principais resultados do Projecto "Imigrantes de Leste em Portugal: da migração à inserção", desenvolvido pelo CESIS - Centro de Estudos para a Intervenção Social, para a Fundação para a Ciência e Tecnologia. Tratando-se de uma corrente migratória muito recente, a disponibilidade de dados de caracterização é, ainda, muito insipiente. Como tal, privilegia-se, no texto, a apresentação de alguns dados de caracterização global relativamente a esla população. O enfoque ocorre, sobretudo, nas estruturas familiares, motivos para migrar e perspectivas de retorno, contexto de residência, situação face à privação, níveis de qualificação escolar, competências linguísticas ao nível da língua portuguesa, e inserção profissional.
\end{abstract}

Palavras-chave: migraçōes; imigrantes de leste

\section{Introdução}

As migrações fizeram, desde os primórdios, parte das sociedades humanas. Merece, aliás, consenso a ideia de que a colonização do planeta se lenha feito através de vagas migratórias a partir do que é hoje o continente africano.

Apesar de denolar evidentes alterações ao longo do tempo, a história é povoada de movimentações populacionais, que por motivos vários, económicos ou militares, com um carácter permanente, temporário ou sazonal, compuseram o mosaico populacional actual.

As migrações internacionais são, sem dúvida, uma questão fundamental e estrulural na sociedade contemporânea. Num mundo crescentemente caracterizado por redes de carácler global, as movimentações internacionais de população constituem um padrão estabelecido, resultado de motivações militares, políticas ou económicas e com uma variedade de implicações aos mais variados níveis: social e também económico e político.

Segundo dados do "World Migration Report" de 2003 (IOM, 2003), uma em cada 35 pessoas é migrante, estimando-se que, no ano $2000,2,9 \%$ da população mundial se enquadrasse na categoria de migrante internacional, correspondendo a 175 milhões de indivíduos, valor que poderá atingir os 2:30 milhões em 2050.
No contexto da União Europeia, e segundo estimalivas do Eurostat, para 2000 (Eurostat, 2003), havia 18,8 milhões de estrangeiros ( 13 milhões dos quais não nacionais da União Europeia), correspondendo a $5 \%$ da população, o que equivale a um aumento de $72 \%$ face a 1995. Anualmente, entram cerca de 880 mil imigrantes legais na União. Essa é, porém, apenas uma das faces da realidade. Estimativas da Europol apontam para 500 mil pessoas entrando ilegalmente, por ano, na União Europeia.

Num contexto de baixíssima natalidade a imigração é, aliás, responsável por cerca de $70 \%$ do aumento populacional registado na União Europeia (Soares, 2003; Eurostat, 2003). Porlugal não é excepção, tendo a imigração sido responsável por $2 / 3$ do crescimento populacional porluguês entre 1997 e 1999. Os anos que se seguiram contribuíram para o acentuar deste fenómeno e, em 2002, de acordo com estimativas do INE, a imigração terá sido responsável por $90 \%$ do crescimento populacional do país.

E a imigração é, de faclo, apontada como fundamental para uma União Europeia (cada vez mais) envelhecida e com taxas de nalalidade bem abaixo dos níveis de reposição geracional, havendo quem defenda que "numa perspectiva de longo prazo, a imigração deve ser encarada como um dos instrumentos estratégicos que permilirão à União Europeia fazer face ao envelhecimento e aos desequilíbrios demográficos." (Fotakis, 2003).

" Sociólogo. Investigador no CESIS - Centro de Estudos para a Intervenção Social. Contacto:pedro.perista@cesis.org 
Estima-se que, entre 2010 e 2030, o ritmo de saídas do mercado de trabalho aumente de forma constante, gerando, ano após ano, uma pressão acumulada tanto no mercado de trabalho como no financiamento das pensões.

Dada a ligação entre emprego e sistema de pensões, seria necessária uma taxa anual média, constante, de $1,37 \%$ de entradas líquidas para o emprego entre 2000-2040, mantendo-se constantes os restantes factores, para equilibrar a partida dos "baby boomers" (Fotakis, 2003).

\section{A Imigração em Portugal}

Portugal, sendo tradicionalmente um país de emigração, tem vindo a assumir, contudo, uma componente de imigração (crescentemente) importante. De facto, no ano 2003, tinham autorização de residência em Portugal, 250697 indivíduos.

Com a inclusão dos titulares de uma autorização de permanência, ascendiam a 434548 os cidadãos estrangeiros residentes em Portugal de forma legal, o que correspondia a mais de $4 \%$ da população do país.

Os movimentos migratórios que têm Portugal como destino têm sofrido mudanças importantes ao longo das últimas décadas, correspondendo ao estabelecimento de diferentes correntes migratórias com origens sobretudo nos designados países africanos de língua oficial portuguesa (PALOP), no Brasil e na própria Europa. E, de facto, até há cerca de três décadas, a grande maioria dos imigrantes era de origem europeia, representando cerca de $75 \%$, em 1970, e rondando ainda os $67 \%$ em 1975.

É, pois, somente na segunda metade da década de 70 que se assiste a uma maior diversificação das correntes migratórias, que corresponde, igualmente, à intensificação das mesmas. Aos fluxos que têm uma origem económica juntam-se, após a descolonização, os refugiados e os chamados retornados. Assim, em 1980, são já mais de 58000 os estrangeiros residentes em Portugal, sendo que destes só cerca de $30 \%$ são europeus, representando os africanos $47,8 \%$ do total.

Dez anos depois, o número de estrangeiros quase tinha duplicado, registando-se uma alteração na origem destes processos de mobilidade, já que é durante a década de 80 que a imigração de natureza laboral assume expressão mais notória. Este tipo de migração consolida-se no que diz respeito aos cabo-verdianos e alarga-se a outros países africanos, especialmente Angola e Guiné-Bissau, e ao Brasil.

A década de 90 vai assistir à continuidade do crescimento do número de estrangeiros em Portugal. É essencial, porém, realçar que é nesta década que decorrem os dois primeiros processos de legalização extraordinária de imigrantes, ocorridos em 1992 e 1996.

O final da década de 90 vem introduzir novas alterações ao panorama imigratório português. A par da continuidade na imigração proveniente dos PALOP e de um reforço da imigração proveniente do Brasil, surgiu um novo fluxo que veio ter consequências importantíssimas: a imigração com origem nos países do leste europeu.

No entanto, os dados oficiais referentes à imigração até 2001, dizendo apenas respeito a autorizações de residência, não cobriam a esmagadora maioria dos imigrantes de Leste em Portugal, legais em Portugal apenas enquanto fosse válido o visto de turismo e remetidos para a ilegalidade sempre ou quase sempre que tal não se verificasse.

Desta forma, no final de 1999, e segundo dados do Serviço de Estrangeiros e Fronteiras, referentes apenas aos estrangeiros com a residência legalizada, residiam, em território português, 2422 indivíduos oriundos do Leste da Europa ${ }^{1}$, valor que, em 2001, apenas tinha subido para 2578. Só com o processo de regularização ocorrido em 2001, os dados estatísticos deixaram perceber a verdadeira magnitude deste fenómeno migratório, que o senso comum dava já a entender há algum tempo.

Assim, no final de 2001 encontravam-se legalmente em Portugal 74 409 indivíduos oriundos da Europa de Leste, dos quais 71831 dispunham de uma autorização de permanência. Em 2002 e 2003, obtiveram autorização de permanência em Portugal 24 291 e 7142 europeus de leste, respectivamente, totalizando, no período, de 2001 a 2003, 103 264 indivíduos. Dos mais de $108 \mathrm{mil}$ indivíduos oriundos da Europa de Leste que se encontravam legalmente em Portugal, no final de 2003, 95,5\%, dispunham de uma autorização de permanência. É ainda de realçar que as autorizações concedidas a imigrantes de leste representaram mais de metade $(56,2 \%)$ do total de autorizações de permanência concedidas.

\footnotetext{
${ }^{1}$ Esta definição inclui cidadãos da Ex-União Soviética, Ex-Jugoslávia, Albânia, Bulgária, República Checa, Eslováquia, Hungria, Polónia e Roménia.
} 
Dentro da designação "imigrantes de leste" há, porém que distinguir diferenças significativas em termos da expressão da presença de diferentes nacionalidades em território português. Cerca de $60 \%$ do total de autorizações de permanência concedidas a oriundos do leste europeu foram atribuídas a ucranianos, registando as restantes nacionalidades mais representadas, valores comparativamente mais baixos. A segunda comunidade mais representativa é a da Moldávia, que representa pouco mais de 10\%, seguindo-se a romena com cerca de $10 \%$.

A imigração do leste europeu veio, pois, introduzir alterações importantes no panorama imigratório português. Desde logo, a dimensão do fluxo veio atenuar a importância relativa da imigração vinda dos PALOP, claramente maioritária até então e foco de atenção quase exclusiva a este respeito, quer para o poder político, quer para as entidades não governamentais actuando no terreno, passando pelas entidades do poder central e local com responsabilidade na matéria.

Por outro lado, ressalta claro que a imigração do leste veio introduzir um carácter de difusão pelo país muito maior do que o que existia anteriormente. Se a Área Metropolitana de Lisboa continua, apesar de tudo, a ser a principal receptora deste fluxo, é-o com uma intensidade menor.

De acordo com dados do SEF, relativos aos titulares de autorizações de residência, em 2002, o distrito de Lisboa, por si só, concentrava mais de metade $(53,9 \%)$ dos imigrantes. Dados da Inspecção-geral do Trabalho, relativos à população estrangeira com contratos registados para obtenção de autorização de permanência, mostram que o distrito de Lisboa agregava apenas 34,5\% desta população de nacionalidade romena, $27,9 \%$ da de nacionalidade moldava e $18,1 \%$ da de nacionalidade russa. Entre os Ucranianos, exactamente a comunidade mais representativa, esse valor era de apenas $18,8 \%$.

A dispersão geográfica induzida pela imigração de leste pode ainda ser deduzida ${ }^{2}$ a partir dos dados relativos ao aumento da população estrangeira nos vários distritos do país. Assim, com a figura das autorizações de permanência, e embora se tenha de realçar que os quantitativos de partida eram relativamente baixos, distritos como Portalegre $(+258 \%)$, Évora $(+323 \%)$, Beja $(+188 \%)$, Castelo Branco $(+193 \%)$, Viseu $(+155 \%)$, Guarda $(+151 \%)$, Vila Real $(+116 \%)$, Bragança $(+137 \%)$ e Santarém $(+526 \%$ !) viram mais que duplicar o número de imigrantes presentes nos seus territórios. A dispersão abrange não só o território continental mas também as Regiões Autónomas da Madeira e dos Açores que registaram aumentos de $115 \%$ e $67 \%$, respectivamente.

Outra característica "inovadora" da imigração de leste prende-se com a maior diversificação dos sectores do mercado de trabalho em que se inserem estes indivíduos. Apesar de os sectores da construção e dos serviços pessoais e domésticos concentra-

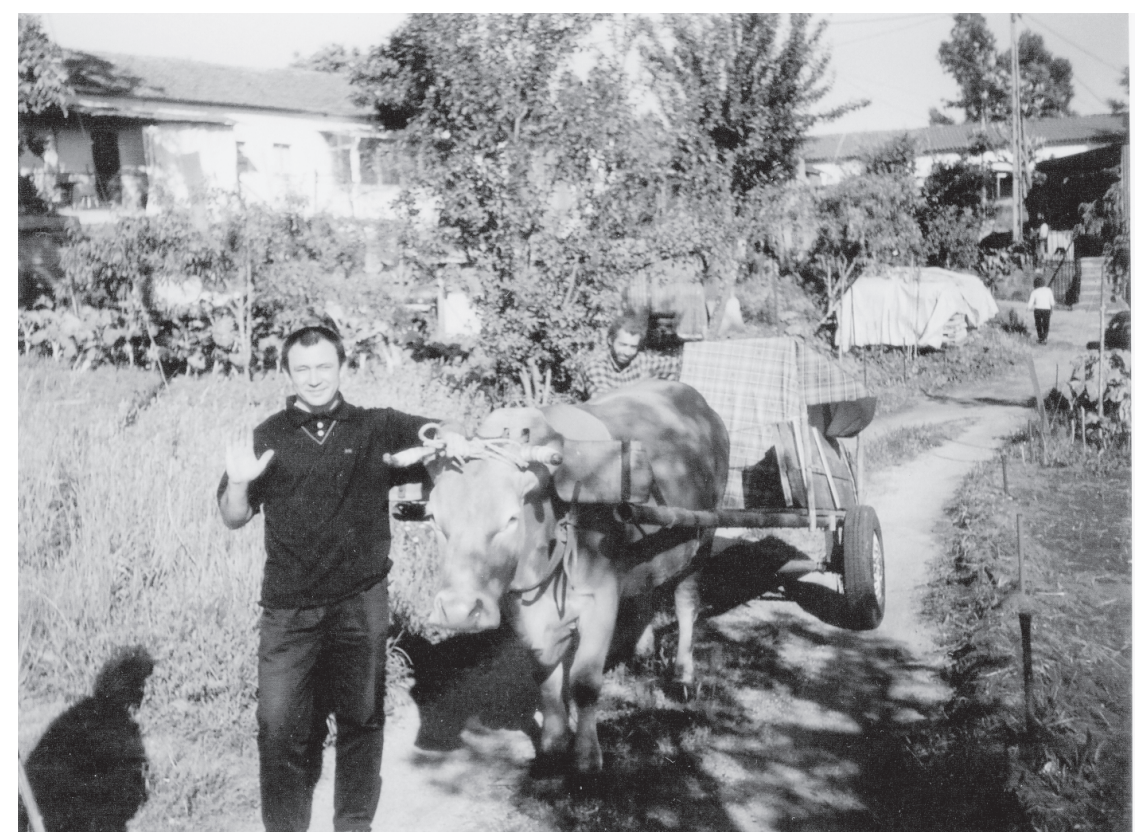

Foto CESIS

\footnotetext{
${ }^{2}$ Pelo peso relativo desta população no total do aumento de população estrangeira em Portugal.
} 
rem também a maioria destes imigrantes, é visível alguma presença na agricultura e na indústria transformadora, muitas vezes com impactos extremamente acentuados em sectores praticamente abandonados pela mão-de-obra nacional.

A maior dispersão geográfica desta imigração, bem como o seu crescimento extremamente rápido vêm colocar questionamentos em relação às perspectivas clássicas de constituição de fluxos migratórios a partir de redes migratórias concentradas territorialmente. A configuração da imigração de leste em Portugal indicia uma característica presente nos fluxos de migração laboral ocorridos a partir da década de 80 e revelada por estudos noutros países, e que diz respeito à constituição dos fluxos mais "por via de um recrutamento organizado do que pela lenta acumulação de percursos autoconstruídos" (Pena Pires, 2002).

\section{A Pesquisa Empírica}

A população inquirida neste estudo foi constituída por 166 indivíduos. Destes, a maioria era de nacionalidade ucraniana $(47,6 \%)$, sendo os cidadãos moldavos a segunda maior comunidade $(20,5 \%)$ enquanto que os nacionais da Rússia ocuparam a terceira posição $(14,5 \%)$. Foram ainda inquiridos cidadãos da Geórgia, Roménia, Bielorússia, Bulgária, Usbequistão, Cazaquistão, República Checa, e Quirguízia. A inquirição ocorreu entre os meses de Junho e Setembro de 2003 e assentou num questionário composto por 166 questões, maioritariamente fechadas, mas que incluía também um conjunto de perguntas abertas que foram posteriormente categorizadas.

Em termos residenciais quase todos os inquiridos residiam na Área Metropolitana de Lisboa. Lisboa era o concelho onde residiam mais inquiridos - cerca de um em cada três - repartindo-se os restantes por outros nove concelhos da área metropolitana: Loures, Odivelas, Cascais, Amadora, Almada, Barreiro, Mafra, Sintra e Vila Franca de Xira.

Um primeiro resultado que importa salientar é o carácter, de facto, muito recente desta corrente imigratória. Em consonância com os dados oficiais do SEF, os imigrantes presentes na amostra começaram a chegar a Portugal a partir de 1997, coincidindo o maior número de entradas com os anos de 2000 e, sobretudo, 2001, o ano da regularização extraordinária de imigrantes.

Os dados da amostra parecem indicar alguma diferenciação em termos de nacionalidade no que respeita a tempos de chegada ao nosso país, revelando uma chegada mais cedo por parte de Moldavos, sobretudo até 2000, ao passo que, entre os Ucranianos, a chegada parece ter-se processado principalmente em 2000 e 2001. Os imigrantes das restantes nacionalidades terão chegado sobretudo a partir de 2001.

Verifica-se também, desde já, uma diferenciação por sexo. Apesar de o período temporal em causa ser muito curto (apenas seis anos, de 1998 a $2003^{3}$ ), e de o período onde existe uma diferenciação significativa ser ainda mais curto (de $2000 \mathrm{em}$ diante), verifica-se uma chegada mais tardia das mulheres em relação aos homens, o que parece querer indicar, por um lado, alguma tendência de recomposição familiar - mais de metade das mulheres $(55,6 \%)$ vieram para Portugal depois dos cônjuges e, destas, 53,3\% fizeram-no depois de 2001 - e por outro, a vinda mais recente de mulheres sozinhas, solteiras. Em termos gerais é possível constatar que uma em cada cinco mulheres chegou a Portugal durante o ano de 2003, face a menos de $1 \%$ dos homens $(0,9 \%)$.

De qualquer forma, a distribuição da amostra por sexo segue o padrão correspondente a uma população nas primeiras fases do processo migratório, predominando os homens, que representavam mais de $2 / 3(69,9 \%)$, face a $30,1 \%$ de mulheres. A sobrerepresentação masculina é mais evidente entre os inquiridos da comunidade moldava $(82,4 \%)$, havendo uma maior feminização entre os inquiridos das outras nacionalidades ${ }^{4}$, onde as mulheres representam $37,9 \%$.

As características de uma população nas primeiras fases do processo migratório voltaram a sobressair na distribuição etária. Todos os inquiridos se encontravam em idade activa, oscilando as suas idades entre os 15 e os 58 anos. No entanto, apesar do limite superior se situar quase nos 60 anos, tra-

\footnotetext{
3 Apenas um inquirido afirmou ter chegado antes de 1998.

${ }^{4}$ Optou-se, por razões operacionais, por manter, enquanto categorias de análise, a população ucraniana, moldava e russa, agregando-se as restantes nacionalidades.
} 
tava-se de uma população extremamente jovem, sendo que $3 / 4$ tinha, no máximo, 41 anos. Um em cada quatro tinha 28 anos ou menos, situando-se quer a média, quer a mediana das idades, nos 36 anos.

Um facto que parece importante mencionar prende-se com o facto de, apesar de tudo, se encontrar um espectro de idades relativamente alargado, o que conjugado com o carácter extremamente recente desta migração, parece-nos indicar a generalização da emigração a diferentes cohortes etárias. De facto, se cerca de um em cada três inquiridos tem entre 25 e 34 anos, mais de ${ }^{1 / 3}$ tem entre 35 e 44 anos, havendo mesmo cerca de um em cada seis com uma idade igual ou superior a 45 anos.

Mais de $2 / 3$ dos inquiridos $(68,1 \%)$ afirmaram ser casados ou juntos e cerca de um em cada quatro, solteiro (25,9\%), sendo os divorciados/separados $(2,4 \%)$ e os viúvos $(3,6 \%)$ categorias quase residuais. Vale a pena, a este respeito, salientar a sobrerepresentação de separadas/divorciadas e de viúvas entre as mulheres ( $14 \%$ no total, face a $2,6 \%$ de homens nas mesmas situações), reflexo de uma situação em que, não se verificando a situação mais tradicional da migração primeira do homem, é a mulher que o faz.

A estrutura familiar mais representativa no contexto da amostra era a dos agregados compostos por elementos não aparentados, muito embora um em cada cinco inquiridos se enquadrasse numa família nuclear com filhos. Ao contrário do que acontece com outras populações imigrantes, nomeadamente com populações originárias dos PALOP, a proporção de famílias alargadas e extensas encontrada foi relativamente reduzida. Comparando com o total da população portuguesa, e de acordo com o Censo de 2001, as famílias extensas e alargadas representavam $12,7 \%$ do total de famílias.

Embora os agregados compostos por elementos não aparentados sejam o agregado mais representativo em todas as nacionalidades consideradas, o seu peso relativo em cada uma delas é bastante diferente. Assim, se representa 44,8\% dos agregados dos nacionais de "outros países" e mais de metade dos agregados dos ucranianos $(51,9 \%)$, representa apenas $1 / 3$ dos agregados dos inquiridos russos e 29,4\% dos agregados dos moldavos.

Neste último caso, o proporção dos que vivem em famílias nucleares com filhos é também de 29,4\%. É também entre moldavos, bem como entre os nacionais de "outros países" que as famílias extensas são mais frequentes (11,8\% e 13,8\%, respectivamente), não se registando este tipo de agregado entre os ucranianos.

São sobretudo os homens que vivem isolados $(8,7 \%$, face a $4,1 \%$ das mulheres) e em agregados compostos por elementos não aparentados $(50,4 \%$ face a $26,5 \%$ ), estando as mulheres sobrerepresentadas nas restantes categorias.

Esta é uma migração claramente económica. A razão explicitada para migrar prendia-se, na maioria dos casos $(79,4 \%)$, com a tentativa de fuga a uma situação socioeconómica precária no país de origem, onde o emprego escasseia ou é extremamente mal remunerado, não sendo suficiente para fazer face às despesas. A fuga à instabilidade sociopolítica foi referida por apenas $2,4 \%$ dos inquiridos, representando a reunião familiar já 5,5\% das respostas (16\% entre as mulheres).

É de salientar, porém, que o valor relativo à reunião familiar diz respeito apenas às respostas expressas nesse sentido e que poderá subir para o dobro se considerarmos aqueles cujo cônjuge já se encontrava em Portugal quando para aqui migraram (10,8\%). Se a este valor se juntar o número daqueles cujo cônjuge veio depois e o número dos que migraram para Portugal em conjunto com o cônjuge, verificamos que $61,9 \%$ dos inquiridos casados/juntos tinha o cônjuge a residir consigo em Portugal, o que é, sem dúvida, assinalável tendo em conta o carácter recente do fenómeno.

A presença de familiares em Portugal é o principal motivo apontado por $17,5 \%$ dos inquiridos (36\% das mulheres) para terem escolhido o país como destino migratório. O motivo mais referido para a escolha de Portugal como destino para a migração foi, porém, a facilidade de legalização $(28,9 \%)$, mais referido até do que a presença no país de amigos ou conhecidos $(26,5 \%)$.

Mas é importante notar que estas facilidades foram referidas por todos os inquiridos, qualquer que seja o ano da sua vinda para Portugal. Mesmo cerca de um em cada seis inquiridos que vieram depois de 2001 e que, teoricamente, encontrariam maiores dificuldades neste campo, apontaram as facilidades de legalização como principal motivo para a escolha de Portugal.

Apesar de tudo, cerca de um em cada cinco inquiridos $(19,1 \%)$ aponta o processo de legalização como uma das duas principais dificuldades que 
sentiu quando chegou a Portugal. Os principais problemas referidos relacionam-se, porém, com a barreira linguística, referida por mais $\mathrm{de}^{2 / 3}$ dos inquiridos $(67,3 \%)$ e o encontrar de trabalho, referido por quase metade $(45,7 \%)$ da população da amostra. Comparativamente, o conseguir um local para morar terá sido menos problemático, sendo uma dificuldade referida por apenas $17,3 \%$.

O regresso ao país de origem é algo que dividia a amostra. De facto, se 42,8\% dos inquiridos afirmou ter planos de regresso ao país de origem, $47 \%$ afirmou o contrário, sendo cerca de $10 \%$ os que afirmaram não saber.

São sobretudo os homens e os indivíduos mais velhos (entre os 45 e os 58 anos) os que mais afirmam ter planos de regresso ao país de origem. O maior tempo de permanência em Portugal parece ter efeitos ao nível da existência destes planos, sendo os inquiridos vindos antes do ano 2000 os que menos afirmam a existência de planos $(29,2 \%)$, para o que poderá contribuir não só uma maior habituação à vida em Portugal, potencialmente originadora de uma maior tendência para a permanência, mas também o facto de parte dos imigrantes chegados nessa altura com perspectivas de retorno ter já partido sendo a maior parte dos que ficaram, indivíduos sem planos de retorno.

Três em cada quatro inquiridos que afirmaram ter planos de retorno estabelecia um prazo máximo de cinco anos para o fazer, e metade queria mesmo regressar no prazo máximo de dois anos.

$\mathrm{O}$ contexto habitacional de residência da maior parte dos imigrantes inquiridos passava pelo aluguer de uma habitação. A utilização de instalações no local de trabalho, nomeadamente nos estaleiros da construção, tão explorada mediaticamente, foi referida por apenas $3,6 \%$.

É de notar, porém, a grande mobilidade residencial destes indivíduos, visto que apenas um em cada três esteve sempre no mesmo alojamento desde que chegou a Portugal. Esta é uma situação fortemente relacionada com o tempo de permanência no país. Ao contrário do que acontece $(u)^{5}$ com parte dos imigrantes oriundos dos PALOP, que residem/residiram na mesma casa durante décadas, para os imigrantes oriundos do leste europeu a primeira residência parece ser encarada, na maioria dos casos, como uma solução muito transitória que, passado o primeiro impacto, vai sendo substituída por soluções mais convenientes.

É, de facto, possível constatar que a maior permanência dos inquiridos no país, conferindo bases de suporte diferentes das disponíveis à chegada e com um maior conhecimento do parque habitacional $^{6}$, leva a que proporções crescentes dos inquiridos mudem de alojamento. Note-se, no entanto, que cerca de um em cada quatro $(27,3 \%)$ inquiridos chegados durante o ano de 2003 mudaram já de alojamento, o que não deixa de ser assinalável?

Outro factor de diferenciação importante é o sexo, sendo que quase metade das mulheres (48\%) sempre viveu no mesmo alojamento em Portugal, face

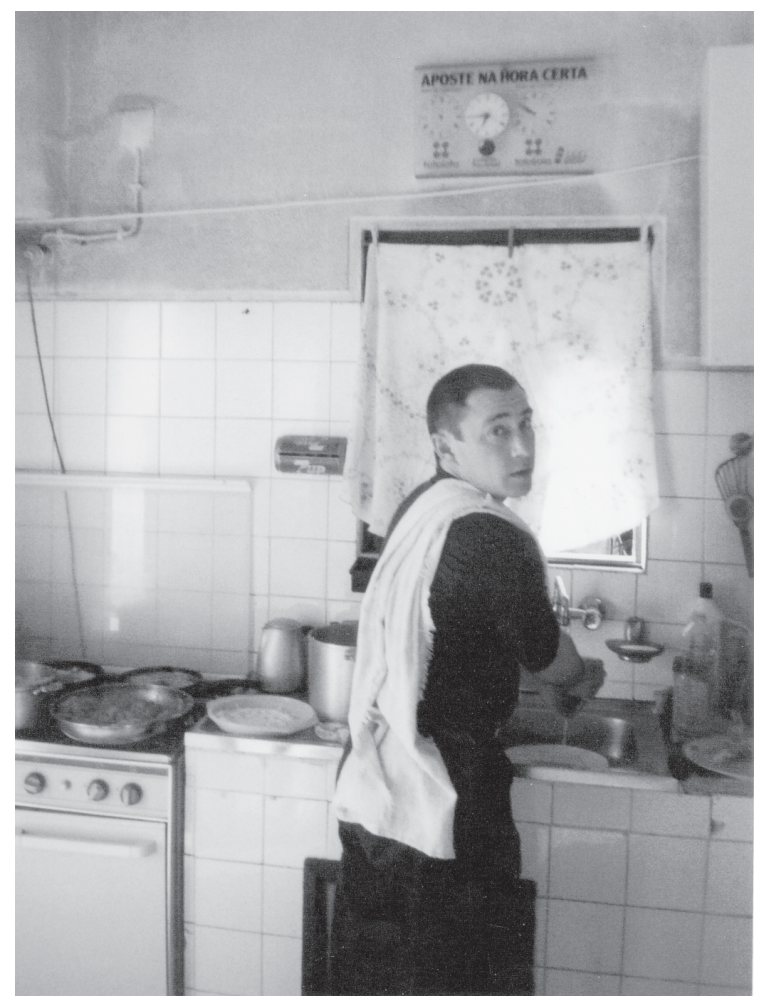

Foto CESIS

\footnotetext{
${ }^{5}$ Os processos de realojamento representaram, para a maioria, a primeira mudança em termos residenciais durante a sua permanência em Portugal.

${ }^{6}$ Como afirmava uma imigrante ucraniana: “quando chegámos, fomos para o Estoril! Não sabíamos... Era tão caro! Depois, fomos sabendo e mudámos."

${ }^{7}$ Um outro factor que pode influenciar tamanha mobilidade pode ser a acção das Máfias. De facto, de acordo com interlocutores privilegiados, muitos são os imigrantes que, uma vez ameaçados pelo crime (mais ou menos) organizado - por vezes trata-se apenas de um dois indivíduos que decidem ameaçar outros imigrantes para obter dinheiro fácil - optam por mudar, de imediato, de casa, de emprego, etc... Isso não é, no entanto, possível aferir através do instrumento aplicado.
} 
a menos de $1 / 3$ de homens na mesma situação $(29,3 \%)$. A esta situação não são alheios, certamente, alguns factores anteriormente referidos, tal como a vinda mais recente das imigrantes, em muitos casos para se juntarem a familiares já aqui residentes e que estão já numa situação habitacional mais definitiva depois de, eles próprios, terem mudado de contexto de alojamento. A análise por situação conjugal parece indicar no mesmo sentido. 70,8\% dos inquiridos casados ou juntos mudaram de alojamento, face a $48,8 \%$ dos solteiros.

Os amigos parecem ser o recurso mais mobilizado para o encontrar de alojamento. Para cerca de metade dos inquiridos, foi através dos amigos que essa situação se concretizou, seja no que respeita ao alojamento actual $(49,1 \%)$, ou ao alojamento anterior $(45,8 \%)$. A principal nota de destaque prende-se com o maior peso do auxílio prestado pelos patrões/empresas para o encontrar do alojamento anterior (19,6\% dos casos), face ao encontrar do alojamento actual $(9,7 \%)$, em favor de soluções (mais facilmente) accionadas com a maior permanência no território de acolhimento como "conhecidos" e "instituições".

O tempo médio de residência no alojamento actual era de quinze meses, valor que variava, principalmente, em função do tempo de permanência em território português - vinte e seis meses para os que aqui residiam desde antes do ano 2000, oito para os que vieram depois de 2001; dezasseis e treze meses para os que chegaram em 2000 e 2001, respectivamente.

No que diz respeito às condições de alojamento, os imigrantes inquiridos parecem dispor de boas condições em termos de equipamentos. No entanto, mesmo assim, é possível constatar que quase $1 / 4$ dos inquiridos se encontra privado de, pelo menos, um bem durável ${ }^{8}$.

Quadro 1 - Indicadores de privação (itens de necessidades básicas, bens duráveis e itens de conforto)

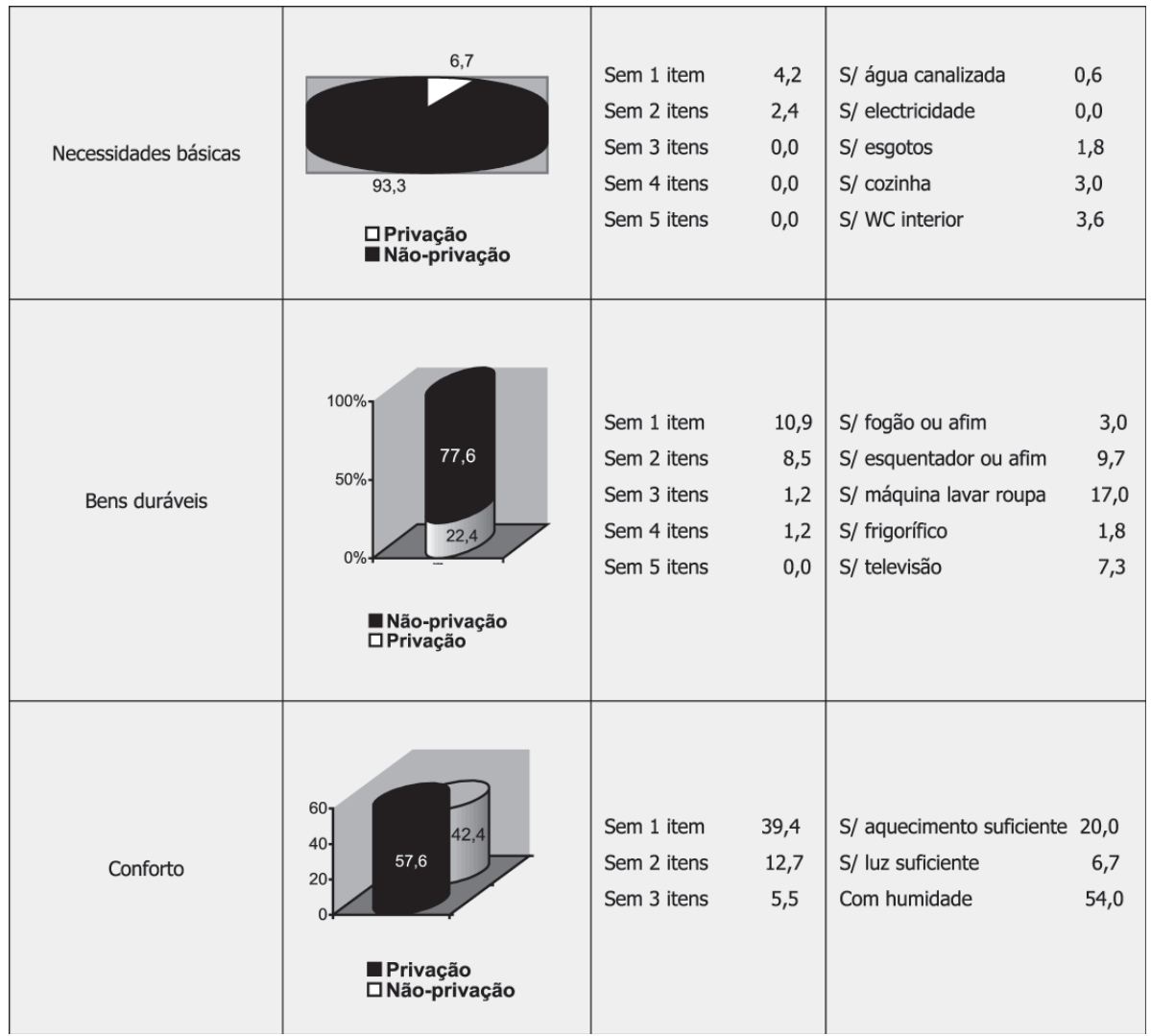

Fonte: Inquérito a Imigrantes de Leste na Área Metropolitana de Lisboa, 2003, CESIS

\footnotetext{
${ }^{8}$ Optou-se por agregar os itens contemplados no questionário em três índices, um relativo a indicadores de necessidades básicas (água canalizada, electricidade, sistema de esgotos, cozinha, casa de banho interior), outro relativo à posse de bens duráveis (fogão ou afim, esquentador ou afim, máquina de lavar roupa, frigorífico, televisão), e outro ainda relativo ao conforto (aquecimento suficiente, luz suficiente, humidade).
} 
É no índice relativo ao conforto que se registam valores de privação mais elevados devidos, sobretudo, à presença de humidade nos alojamentos, e que afecta mais de metade dos alojamentos dos inquiridos.

Comparando com o total da população, é possível verificar que as taxas de privação desta são, em cinco dos oito itens comparados, maiores do que as registados para os imigrantes inquiridos. No entanto, considerando a região de Lisboa e Vale do Tejo, só em dois dos itens, as taxas de privação totais são superiores às dos inquiridos. permite levantar expectativas de uma maior integração a este nível com o passar do tempo e com a procura de soluções habitacionais mais convenientes. É, aliás, sem surpresa, entre os inquiridos residentes em quartos e, sobretudo, em estaleiros de obras de construção que se registam maiores índices de privação. A privação e o gosto/ /desgosto pelo alojamento estão, é claro, fortemente relacionados.

É entre os inquiridos mais velhos (entre os 45 e os 58 anos) que se registam índices de privação mais elevados, o que será parcialmente explicado

Quadro 2 - Indicadores de privação (selecção) para o total da população portuguesa, total da região de Lisboa e Vale do Tejo e para a população inquirida

\begin{tabular}{|l|c|c|c|}
\hline & Total & $\begin{array}{c}\text { Lisboa } \\
\text { e Vale Tejo }\end{array}$ & Inquiridos \\
\hline Sem água canalizada* & 2,1 & 1,0 & 1,3 \\
\hline Sem electricidade* $^{*}$ & 0,5 & 0,3 & 0,0 \\
\hline Sem cozinha* & 0,3 & 0,3 & 2,6 \\
\hline Sem WC interior* & 5,8 & 3,7 & 5,1 \\
\hline Sem fogão** & 0,6 & 0,6 & 1,3 \\
\hline Sem máquina de lavar roupa** & 13,9 & 5,3 & 7,7 \\
\hline Sem frigorífico** & 2,9 & 2,4 & 0,0 \\
\hline Sem televisão** & 2,1 & 1,2 & 7,7 \\
\hline
\end{tabular}

Fonte para a coluna "inquiridos": Inquérito a Imigrantes de Leste na Área Metropolitana de Lisboa, 2003, CESIS

Fontes para as colunas "Total da população" e "Lisboa e Vale do Tejo":

* INE, Recenseamento Geral da População, 2001

** INE, Inquérito aos Orçamentos Familiares, 2000

De facto, a taxa de privação dos imigrantes é maior no que diz respeito à falta de água canalizada, de cozinha, de WC interior, de fogão, de máquina de lavar roupa e de televisão. A falta de alguns destes itens está claramente relacionada com a residência em quartos alugados e que é, entre os inquiridos, muito superior ao registado para o total da população.

Da análise dos dados do questionário ressalta também o carácter multidimensional da privação. Efectivamente, é possível constatar que mais de $80 \%$ dos indivíduos (e, por extensão, os respectivos agregados domésticos) que registam uma situação de privação em termos de necessidades básicas - o mais elementar dos indicadores - estão também privados nas duas restantes áreas consideradas, configurando uma situação de privação extrema em termos habitacionais para cerca de $5 \%$ dos imigrantes da amostra.

O maior tempo de permanência em Portugal configura graus de privação mais baixos, o que pelo facto de ser nesta cohorte que se registam valores mais elevados de alojamento em quartos alugados a senhorios e em estaleiros de obras.

Outro factor potencialmente explicativo desta situação é a perspectiva migratória destes indivíduos. Maioritariamente sem familiares em Portugal são os que mais encaram, como se verificou anteriormente, o regresso ao país de origem, num prazo máximo de cinco anos, e os que, com maior frequência, enviam dinheiro para o país de origem reduzindo ao máximo, os gastos em Portugal.

No que diz respeito à situação dos inquiridos face à escolaridade, foi possível verificar que todos frequentaram a escola, tendo mais de um em três completado o ensino superior $(36,3 \%)$. Quase metade $(49,1 \%)$ completou um curso técnico/profissional. É de realçar, pois, que apenas 10,4\% não completou um curso superior ou técnico/profissional $^{9}$, o que representa uma diferença abissal em relação à população portuguesa.

\footnotetext{
${ }^{9}$ Contabiliza-se ainda $3,7 \%$ de inquiridos com situação confusa decorrente de discrepâncias entre número de anos de escolaridade e formação completada (por exemplo um curso superior completado tendo o inquirido apenas dez anos de escolaridade) e que, por esse facto, foram colocados numa categoria à parte.
} 
De facto, considerando a população total, e de acordo com o Recenseamento de 2001, apenas 6\% da população com 15 ou mais anos tinha completado o ensino superior, havendo $0,6 \%$ com um curso médio. 30,2\% da população tinha completado apenas o $1 .^{\circ}$ ciclo. 60,3\% desta população tinha completado, no máximo o ensino básico.

Também ao contrário do que acontece na população portuguesa, é possível verificar que, quanto mais velhos os inquiridos, maior o seu nível de escolaridade, situação para a qual podem concorrer dois factores. Por um lado, uma possível maior generalização da decisão de migrar entre os indivíduos mais novos ao passo que entre os mais velhos tenderão a sair sobretudo os mais escolarizados. Por outro, os reflexos do colapso do Bloco de Leste e dos seus efeitos sobre o sistema de ensino e percurso escolar dos indivíduos. A análise por género revela-nos a predominância de formação superior entre as mulheres $(54,2 \%)^{10}$, predominando entre os homens o curso técnico/profissional $(56,5 \%)^{11}$.

No que respeita ao domínio da língua portuguesa, a maior parte dos inquiridos faz uma avaliação mediana do seu desempenho, à excepção da escrita, onde quase metade se posiciona no escalão mais baixo. A competência que os inquiridos consideram estar mais desenvolvida é a compreensão, que corresponde não só à primeira fase da aprendizagem de uma língua mas também ao instrumento mais essencial em termos laborais.

Gráfico 1 - Competências linguísticas no domínio do Português (avaliação dos próprios)

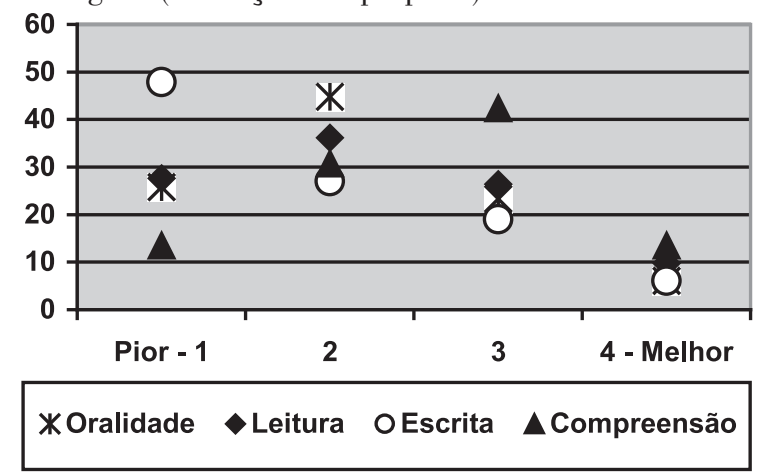

Fonte: Inquérito a Imigrantes de Leste na Área Metropolitana de Lisboa, 2003, CESIS
As auto-avaliações mais positivas são feitas pelos indivíduos mais jovens, pelos que há mais tempo se encontram em Portugal, pelas mulheres e pelos inquiridos de nacionalidade moldava, falantes de uma língua latina e que, por isso, terão, eventualmente, maiores facilidades na aprendizagem do Português.

Seguindo o padrão tradicional de uma população nas primeiras fases de imigração, esta era uma população com taxas de actividade altíssimas. A taxa de actividade feminina, embora mais baixa do que a masculina $(98,2 \%)$ atingia o valor considerável de 88\%. Em termos comparativos, a taxa de actividade relativamente ao total da população portuguesa situava-se em $51,7 \%$ (57,8\% para os homens, $46 \%$ para as mulheres.

Os inquiridos de nacionalidade russa e de "outras nacionalidades" registavam taxas de inactividade comparativamente altas - 12,5\% e 13,8\%, respectivamente - tendo em atenção que a taxa de actividade de ucranianos e moldavos se situava próximo dos $100 \%(98,7 \%$ e $97,1 \%$, respectivamente).

Verificava-se, no entanto, uma diferença assinalável entre estas duas comunidades, e que diz respeito ao desemprego, inexistente entre os moldavos inquiridos, mas que afectava $11,4 \%$ dos ucranianos. Este valor era apenas maior entre os inquiridos de "outras nacionalidades", estando cerca de um em cada cinco destes inquiridos, em situação de desemprego.

Regista-se também uma diferença importante por sexo, na medida em que, para um total de desempregados um pouco superior a $10 \%(10,2 \%)^{12}$, as mulheres registam uma taxa de desemprego que é mais de três vezes superior à dos homens. Verifica-se, pois, uma proximidade relativamente à situação da população portuguesa, não só pelo facto de as mulheres serem das mais afectadas mas também pelo maior desemprego registado entre os mais jovens ${ }^{13}$.

Dos que se encontravam a trabalhar, a maior parte inseria-se em profissões relacionadas com o

\footnotetext{
${ }^{10} 31,3 \%$ tem um curso técnico/profissional, 6,3\% nenhum curso e 8,3\% ignorado.

${ }^{11} 29,6 \%$ tem formação superior, $12,2 \%$ nenhum curso, 1,7\% ignorado.

12 Que corresponde a uma taxa de desemprego de $10,8 \%$, valor bastante superior ao valor de desemprego registado no terceiro trimestre de 2003 para o total da população, que se cifrava em 6,3\% (INE, Inquérito ao Emprego).

${ }_{13}$ É, porém, de realçar a maior severidade com que a questão se coloca para as inquiridas, dado que para o total da população a taxa de desemprego feminina se cifra em $7 \%$, face a uma taxa de desemprego masculina de $5,6 \%$.
} 
sector da construção, seja em situações menos "especializadas" como "servente" e "outras pro-

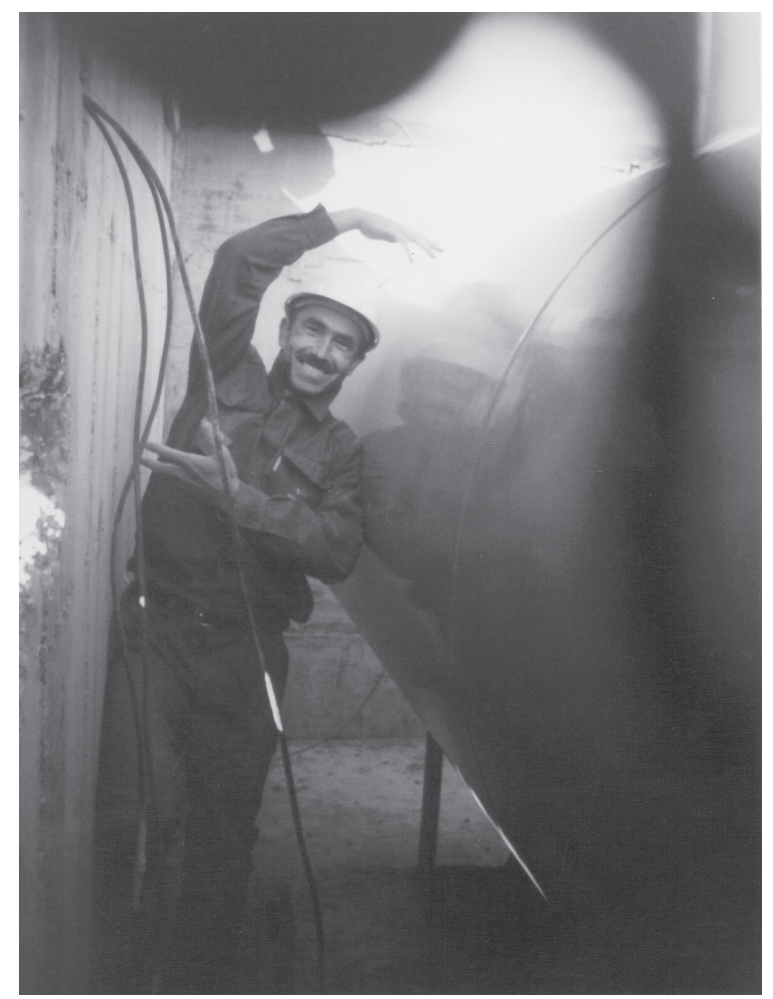

Foto CESIS

fissões da construção", seja em profissões "especializadas"14 como canalizadores ou electricistas.

A actividade exercida é um aspecto em que o género é, obviamente, um grande factor de diferenciação, sendo que nenhuma mulher se encontra representada nas profissões relacionadas com o sector da construção e nenhum homem desenvolve a sua actividade nos serviços domésticos/de limpeza. Para além disso, quase $75 \%$ dos inquiridos que trabalham no sector da restauração são mulheres.

A situação de "servente" era mais representativa entre os imigrantes mais recentes, desaparecendo entre os que vieram antes do ano 2000. $\mathrm{O}$ inverso acontecia com as profissões "especializadas" referidas, reforçando a ideia da passagem de uma situação para outra após algum tempo de ex- periência. Da mesma forma, era entre as imigrantes mais recentes que se verificavam proporções mais elevadas de empregadas domésticas/de limpeza.

O trabalho dos imigrantes inquiridos era, quase exclusivamente, por conta de outrem $(97,2 \%)$, sendo que cerca de três em cada quatro $(76,8 \%)$ tinha um contrato a termo certo. $\mathrm{O}$ contrato sem termo era mais frequente entre os indivíduos mais jovens.

Dada a concentração feminina nos serviços domésticos/de limpeza, registava-se, entre as mulheres, uma maior proporção de trabalhadoras em situações outras, nomeadamente em situações de pagamento à hora.

A influência do tempo de permanência encontrava-se reflectida na qualidade do emprego daqueles que se encontravam a trabalhar, tanto maior quanto mais antiga a vinda para Portugal, quer se tratasse do tipo de contrato ou da realização de descontos para a Segurança Social. 16,7\% dos inquiridos chegados antes de 2000 tinha um contrato sem termo, não havendo inquiridos com outros tipos de contrato precários, ao passo que, dos chegados depois de 2001 , só $3,8 \%$ tinha um contrato sem termo, havendo mais de $1 / 3(34,7 \%)$ com outro tipo de contratos precários (à hora, ao dia, etc.). Da mesma forma, todos os inquiridos chegados antes de 2000 afirmaram fazer descontos para a Segurança Social, face a $65,4 \%$ dos chegados depois de 2001.

O tempo de permanência em Portugal parece constituir-se como um factor de protecção também face ao desemprego. Seja através da possibilidade de acesso, desde logo, a empregos mais estáveis e seguros proporcionada pela chegada mais cedo ao país, ou pelo facto de o maior tempo de permanência (com as mais valias que tal pode originar em termos de conhecimento do mercado de emprego, contactos, domínio da língua, etc.) ter levado ao acesso a empregos de segurança e estabilidade crescente, foi possível constatar que, enquanto que nenhum dos inquiridos vindos antes do ano 2000

\footnotetext{
14 A especialização é relativa dado que, mais do que corresponder verdadeiramente a uma especialização formal, corresponde, em grande parte dos casos, a uma especialização em contexto de trabalho, passando os trabalhadores primeiro pela serventia de pedreiro. Passa também por uma terminologia do sector, fazendo a sua diferenciação nomeadamente em relação às tarefas mais relacionadas com a edificação manifesta das estruturas.
} 
se encontrava desempregado no momento da inquirição, já cerca de um em cada cinco dos chegados depois de 2001 se encontrava em situação de desemprego.

A situação de desemprego era, para a maior parte destes inquiridos, uma situação muito recente (um mês, no máximo), correspondendo, para a quase totalidade, à procura de um novo emprego. Não se verificava, porém, desemprego de circulação. A situação de desemprego vivida no momento da inquirição era a única situação de desemprego nos últimos doze meses para quase todos, havendo apenas um caso que registava já a quinta situação de desemprego.

A situação de desemprego prendia-se sobretudo com a cessação do trabalho por parte da entidade empregadora, seja pelo fim do contrato ou do trabalho, ou mesmo pelo despedimento do trabalhador, situações que primavam, porém, pela informalidade e que faziam com que a maioria não estivesse a receber subsídio de desemprego, precisamente pela ausência de qualquer relação de trabalho estabelecida.

Cerca de dois em cada três dos inquiridos que se encontravam a trabalhar afirmaram-se satisfeitos com o seu emprego/trabalho, situação esta que se prendia, para $21,1 \%$ destes inquiridos, com o facto de ganharem bem, o que se enquadra com os objectivos claros de migrantes económicos.

No entanto, uma razão há, expressa por mais de $1 / 3$ destes inquiridos $(35,8 \%)$, e que foi a mais referida, que foi o gosto pelo trabalho desempenhado, o que pode levantar algumas questões, nomeadamente em relação à desadequação, tanta vezes falada, entre as habilitações e o trabalho desenvolvido por estes indivíduos, tanto mais que $16,5 \%$ referiu que a satisfação com o emprego se devia ao facto de ser aquilo para que dispunha de habilitação.

Esta possível desadequação encontrava-se expressa na resposta mais assinalada para a não satisfação com o emprego, exactamente o facto de não ser aquilo para que o/a inquirido/a se encontrava habilitado $(38,6 \%)^{15}$.

No entanto, o grau de satisfação dos inquiridos com formação superior, apesar de ser o mais baixo $(59,6 \%)$ e bastante inferior aos dos com formação técnica/profissional (69\%), era apenas ligeiramente mais baixo ao daqueles que não completaram formação superior ou técnica/profissional $(61,5 \%)$.

Em jeito de conclusão, é possível realçar que os resultados do estudo vieram infirmar, por um lado, e confirmar, por outro, as imagens que se foram consolidando no senso comum ao longo dos últimos anos. Assim, confirmou-se a ideia de que esta é uma migração de carácter claramente económico, que encontrou em Portugal um dos seus principais destinos, sobretudo devido às facilidades de legalização aqui encontradas pelos inquiridos e que foram exploradas pelos esquemas de auxílio à imigração ilegal.

A população masculina era largamente predominante mas a recomposição familiar era já uma realidade evidente sobretudo tendo em atenção o carácter ainda recente do fluxo. Em termos habitacionais ressaltou clara a baixa prevalência de situações mais vulneráveis, mas mais exploradas pelos media, como o alojamento em estaleiros de obras.

Confirmou-se a integração laboral destes indivíduos sobretudo nos sectores da construção e dos serviços domésticos sendo evidente que o maior tempo de permanência no país parece ser decisivo para o acesso a empregos mais recompensadores.

Finalmente, a questão das habilitações literárias. Esta, é de facto, uma população com um alto nível de escolaridade, muito superior ao da população portuguesa, por exemplo, mas é necessário clarificar que não nem todos têm habilitações de nível superior. $\mathrm{O}$ ensino técnico/profissional ocupa, nesta população, um lugar de destaque, qualificando os indivíduos para o desempenho de um conjunto de profissões que, no nosso país, vão resultando apenas da experiência e de algum esforço autodidacta.

\footnotetext{
${ }^{15}$ Convém, porém, lembrar que tal valor corresponde a apenas $12 \%$ dos inquiridos que se encontram a trabalhar. Os outros principais motivos referidos para a insatisfação com o emprego/trabalho são o ganhar pouco $(29,5 \%)$ e o facto de ser fatigante $(18,2 \%)$.
} 


\section{Bibliografia}

FOTAKIS, C., 2003, “Imigração: Debate sobre a política da União Europeia", Dimensão social e imigração, Cadernos Sociedade e Trabalho, n. ${ }^{\circ} 3$, Lisboa, DEPP/MSST.

IOM, 2003, IOM news - Managing migration: challenges and responses for people on the move, IOM.

JACKSON, J. A., 1986, 1991, Migrações, Lisboa, Escher.

MACHADO, F. L., 1997, "Contornos e especificidades da imigração em Portugal", Sociologia - Problemas e Práticas, n. ${ }^{\circ} 24$.

MACHADO, F. L., 2002, Contrastes e continuidades - migração, etnicidade e integração dos Guineenses em Portugal, Oeiras, Celta Editora.

MYNZ, R., 1995, "Where did they all come from? Typology and geography of European mass migration in the twentieth century", European Population Conference, Milano, United Nations Population Information Network.
PENA PIRES, R., 2003, Migrações e integração: teoria e aplicações à realidade portuguesa, Oeiras, Celta Editora.

PERISTA, P. et al.,1998, Soluções de realojamento para grupos específicos, Lisboa, CESIS, policopiado.

PERISTA, P. et al., 2000, O Lugar do habitat num quadro de interacção entre grupos étnicos minoritários e a sociedade de acolhimento ou o grupo maioritário, Relatório da Fase B, Lisboa, GES-LNEC/CESIS.

PERISTA, P. et al., 2001, Limites e potencialidades da promoção pública de habitação em processos de integração sóciourbanística, Relatório Final, Lisboa, GES-LNEC/CESIS.

PORTES, A., 1999, Migrações internacionais - origens, tipos e modos de incorporação, Oeiras, Celta Editora.

SOARES, R., 2003, "Relatório sobre a situação social na União Europeia", Dimensão social e imigração, Cadernos Sociedade e Trabalho, n. ${ }^{\circ} 3$, Lisboa, DEPP/MSST. 